\title{
A stable nitroxide radical effectively decreases mucosal damage in experimental colitis
}

\author{
F Karmeli, R Eliakim, E Okon, A Samuni, D Rachmilewitz
}

\begin{abstract}
TEMPOL, a cyclic nitroxide stable radical blocks biological damage by breaking chain reactions through termination reaction with free radicals, and by inhibiting the catalytic effect of transition metals. This study tested its protective effect on two models of experimental colitis as free radicals play an important part in their pathogenesis. TEMPOL was given intragastrically immediately after induction of colitis with acetic acid or trinitrobenzene sulphonic acid (TNB) and mucosal damage was assessed one, three, or seven days later. Cellular partition of TEMPOL was determined by electron paramagnetic resonance spectroscopy. In vitro experiments showed that TEMPOL immediately penetrates colonic mucosa and, following its intragastric administration, it persists in both gastric and colonic mucosa for several hours. Intragastric administration of TEMPOL, $0.5 \mathrm{~g} / \mathrm{kg} / \mathrm{bw}$, immediately after intracaecal administration of $5 \%$ acetic acid significantly decreased mucosal lesion area, myeloperoxidase activity, and leukotriene $\mathbf{B}_{4}$ and $C_{4}$ generation when assessed 24 hours after damage induction. Intragastric administration of TEMPOL, $0.5 \mathrm{~g} / \mathrm{kg} / \mathrm{bw}$, immediately after intracolonic administration of $30 \mathrm{mg}$ TNB in $0.25 \mathrm{ml} 50 \%$ ethanol, and once daily thereafter, significantly decreased mucosal lesion area assessed after one, three, and seven days, having no effect on $\mathrm{LTC}_{4}$ generation and affecting colonic weight, myeloperoxidase activity, and $\mathrm{LTB}_{4}$ generation only sporadically. In conclusion, TNB and acetic acid induced colitis can be pharmacologically manipulated by TEMPOL. TEMPOL may be beneficial in the treatment or prevention of inflammatory bowel disease.

(Gut 1995; 37: 386-393)
\end{abstract}

Keywords: TEMPOL, trinitrobenzene sulphonic acid, acetic acid, electron paramagnetic resonance, oxygen reactive species.

The inflamed intestinal and colonic mucosa in inflammatory bowel disease is infiltrated by equally prominent components of neutrophils, macrophages, and lymphocytes. ${ }^{1-3}$ Although the trigger provoking inflammation of colonic mucosa in inflammatory bowel disease is unknown, there is mounting evidence to suggest that interactions between free radicals and redox-active metals play a key part in its amplification. ${ }^{4-6}$ Oxygen derived active species are readily available in the gastrointestinal tract. Their major potential sources include stimulated leucocytes, xanthine oxidase, colonic bacteria, and epithelial lipooxygenase activity. Xanthine oxidase, which catalyses reduction of oxygen, yielding $\mathrm{O}_{2}{ }^{--}$and $\mathrm{H}_{2} \mathrm{O}_{2}$, is activated by proteases released either from inflammatory cells or from dying epithelial cells.

The comparative scarcity of antioxidant enzymes, such as superoxide dismutase and catalase, further amplifies the vulnerability of the colon toward the deleterious activity of the oxygen derived species. ${ }^{78}$ Moreover, the therapeutic effect of 5-ASA in inflammatory bowel disease is ascribed also to its potent function as an antioxidant. 5-ASA is a scavenger of neutrophil derived hypochlorous acid ${ }^{9}$ and an effective intracellular and extracellular scavenger of superoxide. ${ }^{10-12}$

If a radical mediates biological damage, its sequestration by another radical will provide better protection. This strategy has been adopted by using nitroxides to protect cells, ${ }^{13}$ organs, ${ }^{14}$ and whole animals. ${ }^{15}$ Cyclic nitroxides are cell permeable, non-toxic, stable radicals, capable of catalytically dismutating superoxide radicals yielding $\mathrm{H}_{2} \mathrm{O}_{2}$ and molecular oxygen. Nitroxides were recently shown by us to protect the upper gastrointestinal tract against injury induced by various irritants. ${ }^{16}$

In view of the challenge to prevent flare up or to ameliorate the inflammatory response in inflammatory bowel disease, and to acquire a better understanding of the pathogenesis of colonic damage, the protective effect of TEMPOL, a hydrophilic nitroxide radical, was evaluated in experimental colitis.

\section{Methods}

All of the animal studies described here adhere to the standards established by the 'Guide for The Care and Use of Laboratory Animals'.

\section{TNB/ethanol induced colitis}

Male rats (Sprague-Dawley), weighing 200$250 \mathrm{~g}$ and fed ad libitum, were used in all the studies. Inflammation of the colon was induced under light ether anaesthesia by a single intracolonic administration of $0.25 \mathrm{ml}$ of $50 \%$ ethanol containing $30 \mathrm{mg}$ of $\mathrm{TNB}$, as previously described. ${ }^{17}$ The solution was introduced by a catheter with a $0.3 \mathrm{~mm}$ outer diameter placed $7 \mathrm{~cm}$ from the anus. Rats were killed one, three or seven days after the induction of injury. The colon was isolated, a $10 \mathrm{~cm}$ segment of the distal colon proximal to the 
anus was resected, its lumen rinsed with ice cold saline and weighed. A cross section was obtained for histological assessment and the remaining mucosa was scraped, minced, and stored at $4^{\circ} \mathrm{C}$. Samples of these mucosal scrapings were processed for determination of myeloperoxidase activity, leukotriene $\mathbf{B}_{4}$ $\left(\mathrm{LTB}_{4}\right)$, and leukotriene $\mathrm{C}_{4}\left(\mathrm{LTC}_{4}\right)$. Treated rats were given TEMPOL $(0.5 \mathrm{~g} / \mathrm{kg})$ intragastrically immediately after induction of colonic damage and once daily thereafter until death. In another experiment TNB was coadministered intrarectally with $30 \mathrm{mg}$ TEMPOL and rats killed 24 hours later. Apart from saline treated rats, an additional control group of rats was treated with $0.5 \mathrm{~g}$ TEMPOL $/ \mathrm{kg} / \mathrm{bw}$ alone and killed 24 hours later.

\section{Acetic acid induced colitis}

Male rats weighing 200-250 g were fasted for 24 hours. Under light ether anaesthesia, a midline abdominal incision was made, the colon isolated, and the junction of caecum and ascending colon ligated. Two $\mathrm{ml}$ of $5 \%$ acetic acid were injected into the lumen of the colon at its proximal part through a 25 gauge needle, followed by $3 \mathrm{ml}$ of air, which cleared most of the acetic acid from the colon ${ }^{12}$ and the midline incision was closed. Control rats were treated with saline. Treated rats received TEMPOL intragastrically at doses of $0 \cdot 1,0 \cdot 3$, 0.5 , or $0.75 \mathrm{~g} / \mathrm{kg} / \mathrm{bw}$ immediately after induction of damage. Another group of rats received TEMPOL $0 \cdot 1 \mathrm{~g} / \mathrm{kg} / \mathrm{bw}$ intragastrically 30 minutes before damage induction, immediately after damage induction, and then every

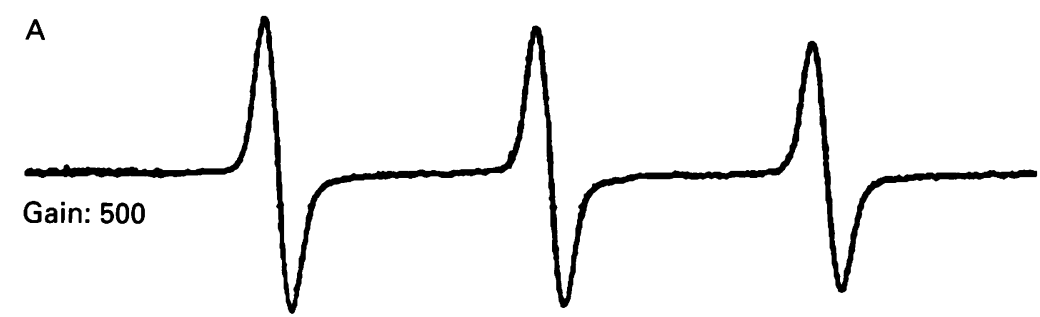

B
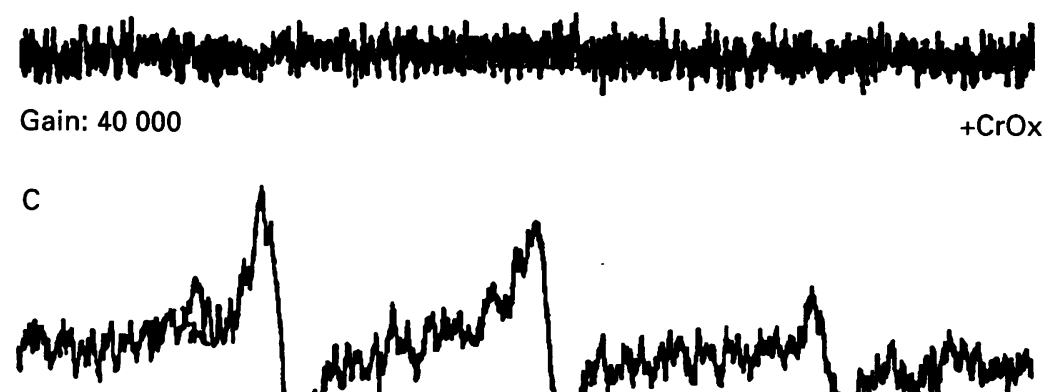

Gain: 40000
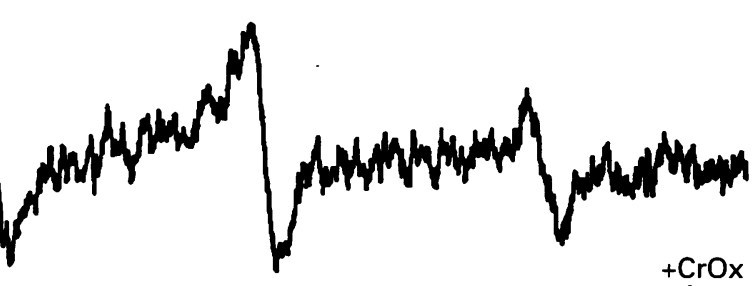

Figure 1: Partition of TEMPOL into the colonic mucosa. Electron paramagnetic resonan spectrum recorded using grooved flat quartz cuvette containing: $(A) 20 \mu l$ solution of $1 \mathrm{mM}$ TEMPOL, (B) same as $(A)+20 \mu \mathrm{CrOx}$, and $(C)$ same as $(B)$ with $16 \mathrm{mg}$ colonic mucosal tissue. Instrument settings were: $9.45 \mathrm{GHz}$ microwave radiation, $100 \mathrm{G}$ field range, $1 \mathrm{G}$ modulation amplitude, $100 \mathrm{kHz}$ modulation frequency, and $20 \mathrm{~mW}$ power of incident microwave. hour for the next three hours. Another group of rats was treated intragastrically with superoxide dismutase $75 \mathrm{U} / \mathrm{g} / \mathrm{bw}$ immediately after damage induction by acetic acid. Control rats in this experiment were given bovine serum albumin $0.15 \mathrm{~g} / \mathrm{kg} / \mathrm{bw}$ intragastrically. In all experiments rats were killed 24 hours later, their colons removed, and handled as with the TNB model.

\section{Assessment of mucosal damage}

Mucosal damage was assessed macroscopically by measuring lesion area expressed in $\mathrm{mm}^{2} /$ rat. All measurements of damage were performed blindly by two observers using a stereomicroscope.

\section{Morphological studies}

Colonic segments were fixed in phosphate buffered formaldehyde, embedded in paraffin wax, and routine $5 \mu \mathrm{m}$ sections were prepared. Tissues were routinely stained with haematoxylin and eosin and blindly evaluated by light microscopy.

\section{Determination of myeloperoxidase activity}

Samples of $200 \mathrm{mg}$ of mucosal scrapings were homogenised three times for 30 seconds each at $4^{\circ} \mathrm{C}$ with a polytron (Kinematica $\mathrm{GmbH}$, Kriens-Luzern, Switzerland) in $1 \mathrm{ml}$ of ice cold $0.5 \%$ hexadecyltrimethyl-ammonium bromide in $50 \mathrm{mM}$ phosphate buffer, $\mathrm{pH}$ 6. The polytron probe was rinsed twice with $1 \mathrm{ml}$ of the buffer and the washings were added to the homogenate. The homogenate was then sonicated for 10 seconds, freeze thawed three times, and centrifuged for 15 minutes at $40000 \mathrm{~g}$. An aliquot of the supernatant was taken for determination of the enzyme activity, as previously described. ${ }^{18}$

\section{Determination of lipooxygenase products}

Samples of $150 \mathrm{mg}$ mucosa were placed in preweighed tubes containing $1 \mathrm{ml}$ of $50 \mathrm{mM}$ phosphate buffer, $\mathrm{pH} 7 \cdot 4$. The mucosa was minced with scissors and centrifuged in an Eppendorf centrifuge for 10 seconds. The pellet was resuspended in $1 \mathrm{ml}$ of the above buffer, vortexed for one minute, indomethacin $(10 \mu \mathrm{g} / \mathrm{ml})$ was added, and the tubes centrifuged for 60 seconds. The supernatants were kept at $-20^{\circ} \mathrm{C}$ until radioimmunoassays were performed. The mucosal capability to generate $\mathrm{LTB}_{4}$ and $\mathrm{LTC}_{4}$ was expressed as $\mathrm{ng} / \mathrm{g}$ wet tissue weight.

\section{Measurement of $\mathrm{LTB}_{4}$}

$\mathrm{LTB}_{4}$ immunoreactivity was determined by radioimmunoassay kit (Amersham, TRK 940). The assay combines the use of high specific activity $\mathrm{LTB}_{4}$ tracer, an antiserum specific for $\mathrm{LTB}_{4}$ (cross reactivity $100 \%$ ), and a leukotriene standard (range $1 \cdot 6-200 \mathrm{pg} /$ tube). The specific binding of tracer is $42.5 \%$ and non-specific binding, $2 \cdot 4 \%$. Fifty per cent 


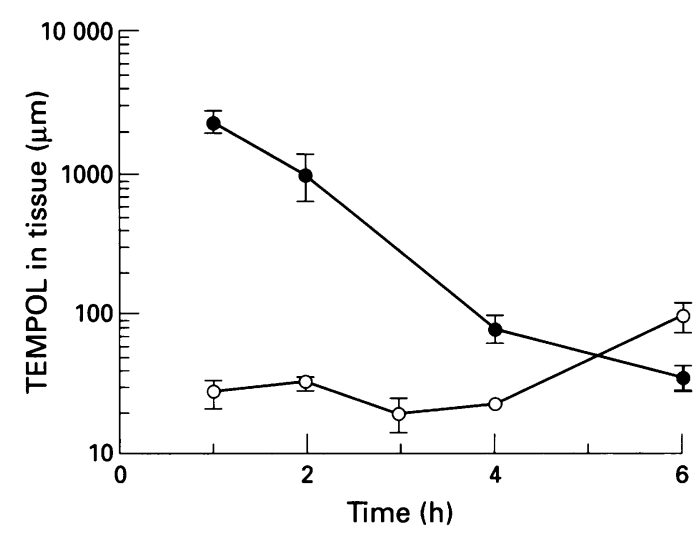

Figure 2: Time dependence of TEMPOL persistence in mucosal tissue. Rats were treated intragastrically with $0.5 \mathrm{~g}$ TEMPOL/kg/bw. After varying time periods the rats were killed and samples (20-50 mg) of mucosal tissue were excised from the stomach and the colon. The tissue samples were weighed, incubated in $1 \mathrm{ml} P B S$, and stored in $-70^{\circ} \mathrm{C}$ until electron paramagnetic resonance measurements. For determination of the nitroxide concentrations in the tissue, the samples were thawed, volumes of $100 \mu$ l were inserted in a Teflon capillary inserted in the spectrometer cavity, the electron paramagnetic resonance signal was monitored, the TEMPOL was calculated knowing the tissue sample weight and presented as mean (SEM) for the stomach (three experiments) (solid symbols) and the colon (six experiments) (open symbols).

$\mathrm{B} / \mathrm{Bo}$ displacement is obtained with $15 \mathrm{ng} /$ tube and $90 \% \mathrm{~B} / \mathrm{Bo}$ displacement with $2 \cdot 2 \mathrm{ng} /$ tube of $\mathrm{LTB}_{4}$.

\section{Measurement of $\mathrm{LTC}_{4}$}

$\mathrm{LTC}_{4}$ immunoreactivity was determined by radioimmunoassay kit (Amersham, TRK 905). The assay combines the use of high specific activity $\mathrm{LTC}_{4}$ tritiated tracer with a monoclonal antibody specific for $\mathrm{LTC}_{4}$. The standard curve covers the range $8-500 \mathrm{pg} /$ tube and was performed in serial dilution. The assay uses highly specific LTC $_{4}$ antiserum (cross reactivity $100 \%$ ) and has low cross reactivity with $\mathrm{LTD}_{4}(<5 \%)$. The specific binding of tracer is $40 \cdot 2 \%$ and non-specific binding, $3 \%$.

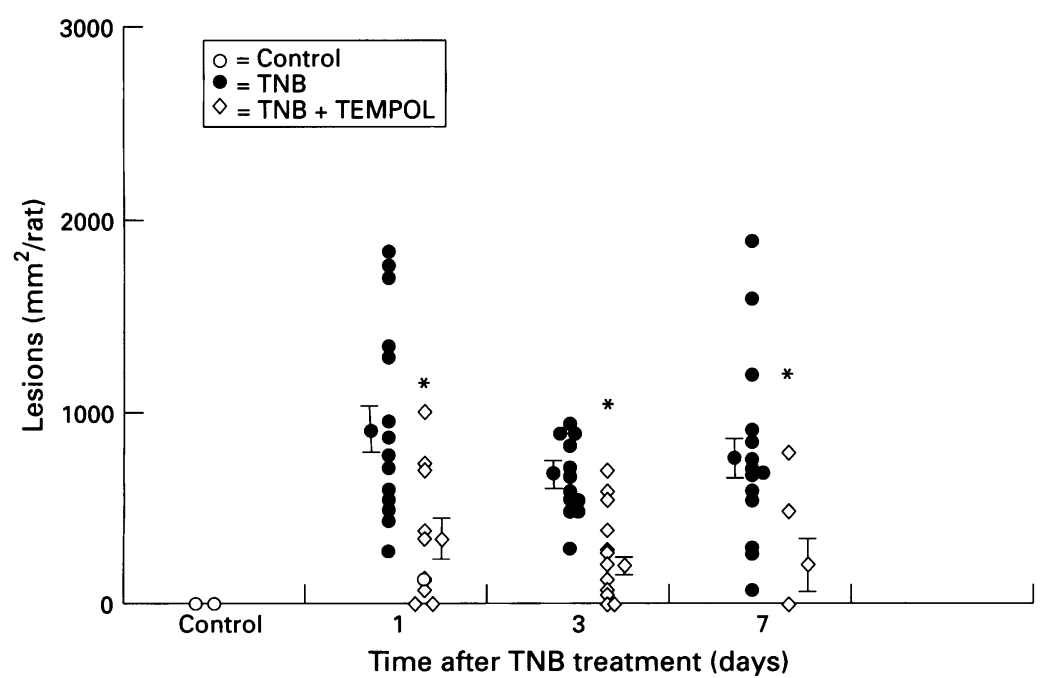

Figure 3: Effect of TEMPOL on lesion area in TNB/ethanol treated rats. Colitis was induced by the intracolonic administration of $0.25 \mathrm{ml} 50 \%$ ethanol containing $30 \mathrm{mg}$ TNB as described in Methods. Treated rats were given TEMPOL $(0.5 \mathrm{~g} / \mathrm{kg})$ intragastrically once daily. Rats were killed 24 hours, 72 hours, or one week after damage induction, the colon isolated, and lesion area in the $10 \mathrm{~cm}$ distal colonic segment was measured. Results are mean (SEM). *Significantly different from TNB treated rats only $(p<0 \cdot 05)$.
B/Bo displacement of $50 \%$ is obtained with $34 \mathrm{ng} /$ tube and $80 \% \mathrm{~B} / \mathrm{Bo}$ displacement with $9 \cdot 5 \mathrm{pg} /$ tube of $\mathrm{LTC}_{4}$.

Electron paramagnetic resonance measurements Samples of colonic mucosa (20-50 mg wet weight) were excised immediately after death and placed in a special groove of a standard quartz made tissue cuvette. Liquid samples were drawn into a gas permeable, Teflon capillary of $0.8 \mathrm{~mm}$ inner diameter. The capillary was inserted into a quartz tube open at both ends and then inserted into the electron paramagnetic resonance cavity. During the experiment the sample within the spectrometer cavity was flushed with air, without disturbing the sample, and the electron paramagnetic resonance spectra were recorded on a Varian E9 X-band spectrometer operating at 9.45 $\mathrm{GHz}, 100 \mathrm{kHz}$ modulation frequency, $1 \mathrm{G}$ modulation amplitude, and $20 \mathrm{~mW}$ microwave power. The concentrations of TEMPOL in the samples studied were assessed using a TEMPOL solution of a known concentration as a calibration standard.

\section{Statistical analysis}

Data are expressed as mean (SEM) and range. Statistical analysis for significant differences was performed according to the Student's $t$ test for unpaired data and the non-parametric Mann-Whitney U test.

\section{Materials}

The acetic acid (Frutarom, Israel), $\mathrm{CrOx}$, tri(oxalato) chromiate(III) $\mathrm{K}_{3}\left[\mathrm{Cr}\left(\mathrm{C}_{2} \mathrm{O}_{4}\right)_{3}\right]$ $.3 \mathrm{H} 2 \mathrm{O}$ was prepared as previously described, 19 TEMPOL, 4-OH-2,2,6,6,tetramethyl-piperidine-1-oxyl, trinitrobenzene sulphonic acid, superoxide dismutase, bovine serum albumin (Sigma Laboratories, Israel), $\mathrm{LTB}_{4}, \mathrm{LTC}_{4}$, radioimmunoassay (Amersham, England) were used.

\section{Results}

Nitroxide's partition into cells

Because TEMPOL is a free radical its concentration in the tissue as well as distribution between intra and extracellular compartments can be readily achieved using electron paramagnetic resonance spectroscopy. To ascertain that TEMPOL does indeed enter the mucosal cells, the effect of paramagnetic line broadening agent, which is excluded from the cells, on the electron paramagnetic resonance signal of the nitroxide was examined. In principle, a distinction between the electron paramagnetic resonance signals arising from intra and extracellular species can be achieved with selective line broadening agents that cannot enter the cells. Tri(oxalato) chromiate(III) (CrOx), which was previously found to be superior to ferricyanide or $\mathrm{Ni}(\mathrm{II}),{ }^{20}$ was used in this study to eliminate the signal of extracellular nitroxides. Upon adding up to $150 \mathrm{mM}$ 


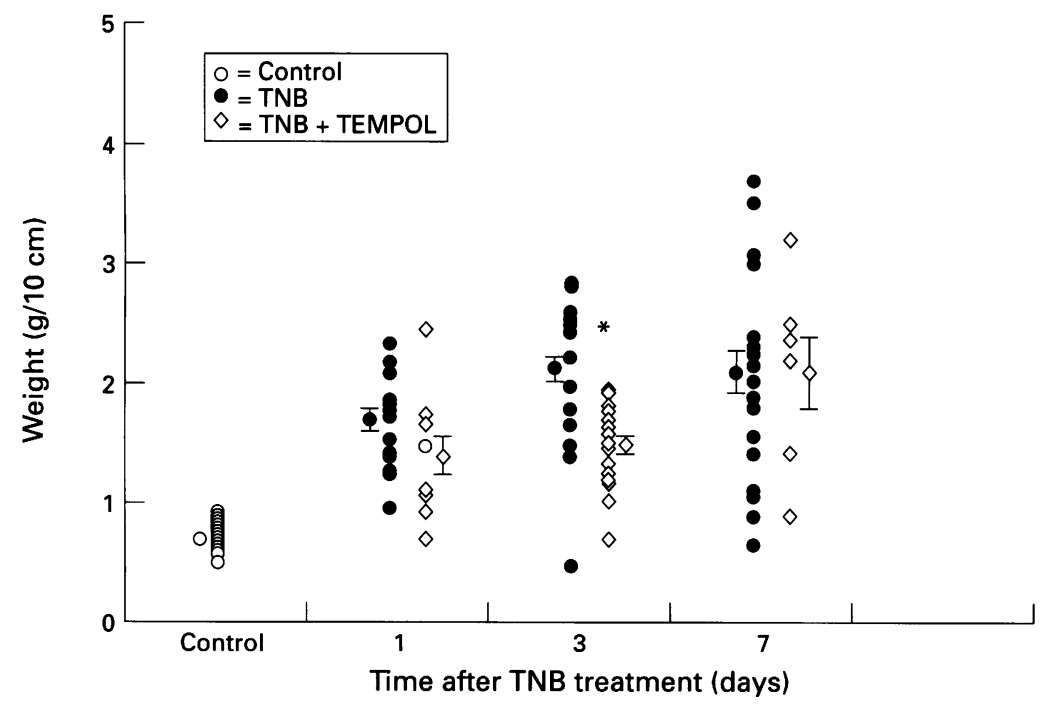

Figure 4: Effect of TEMPOL on colonic weight in TNB/ethanol treated rats. Experimental conditions as detailed in Fig 3. The colon was isolated and its $10 \mathrm{~cm}$ distal segment weighed. Results are mean (SEM). * Significantly different from TNB treated rats only $(p<0.05)$.

reflecting the volume fraction occupied by the cells. The results showed that TEMPOL readily enters the mucosal cells, as previously found for isolated cells in tissue culture. ${ }^{21}$ Assuming that about $30 \%$ of the tissue volume is occupied by mucosal cells, the volume fraction inaccessible for $\mathrm{CrOx}$ was about $10 \%$ of the total volume measured. Taking into account the 1:80 ratio of spectrometer gains, yields a ratio of $1: 8$ for nitroxide concentration inside and outside the cells.

\section{Nitroxide's persistence in the mucosal compartment}

To evaluate the persistence of the nitroxide in the mucosal tissue, we made use of the fact that nitroxides are free radical themselves and as such are observable by electron paramagnetic resonance. A distinction between intra and extracellular radicals is achievable using suitable reagents, which cannot enter the cell and, therefore, affect the electron paramagnetic resonance signal of extracellular species only.

CrOx to $1 \mathrm{mM}$ TEMPOL solution, the electron paramagnetic resonance signal of the nitroxides disappeared. To check whether the nitroxide permeates into the cells a tissue sample of colonic mucosa was introduced into the TEMPOL+CrOx solution. Consequently, the electron paramagnetic resonance signal of TEMPOL was partly restored, showing that part of the radicals are separated from the broadening agent. Figure 1 shows the results of a typical experiment, which compares the electron paramagnetic resonance signal seen upon scanning a sample of $20 \mu \mathrm{l} 1 \mathrm{mM}$ TEMPOL (Fig 1A) with that containing $20 \mu 1$ TEMPOL plus $20 \mu \mathrm{l} \mathrm{CrOx} 300 \mathrm{mM}$ (Fig 1B). Obviously, the TEMPOL signal disappeared. However, the signal was partially restored upon the addition of $16 \mathrm{mg}$ colonic mucosa sample (Fig 1C). As Fig 1 shows, the intensity of the restored signal, caused by intracellular TEMPOL species inaccessible to line broadening, represented only a small fraction of the total signal,

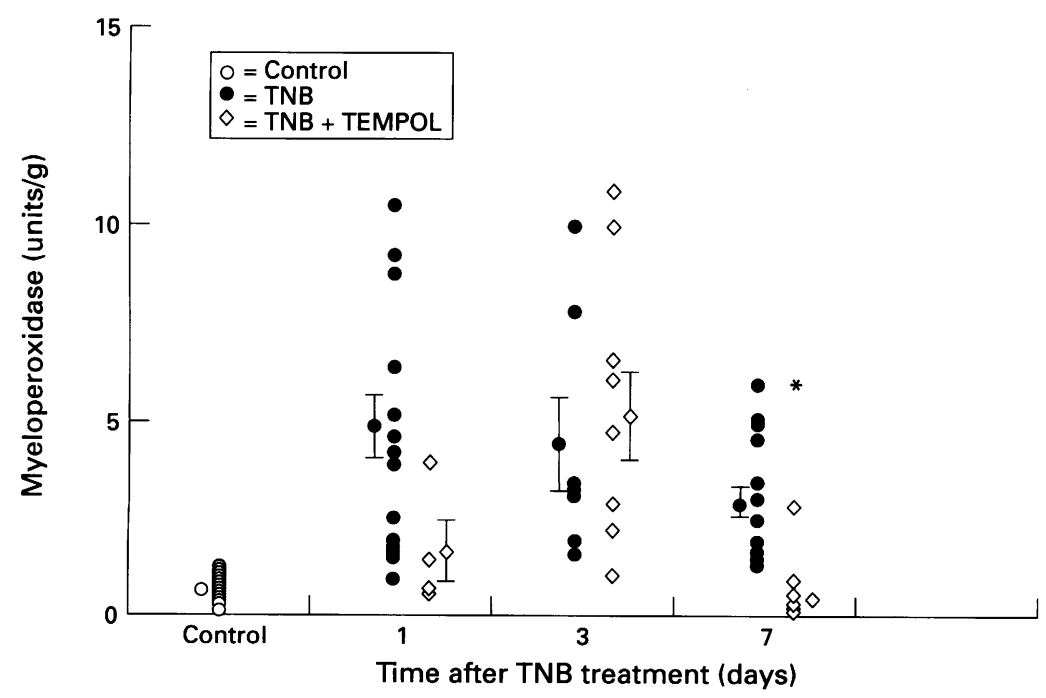

Figure 5: Effect of TEMPOL on colonic myeloperoxidase activity in TNB/ethanol treated rats. Experimental conditions as detailed in Fig 3. The colon was isolated, washed, and the mucosa of the $10 \mathrm{~cm}$ distal colonic segment extracted and myeloperoxidase activity determined as described in Methods. Results are mean (SEM). ${ }^{\star}$ Significantly different from TNB treated rats only $(p<0 \cdot 05)$.
To study the partition and persistence of the nitroxide in the mucosal compartment, rats were treated intragastrically with $0.5 \mathrm{~g}$ TEMPOL $/ \mathrm{kg} / \mathrm{bw}$, then after various time periods the rats were killed, mucosal samples were excised from stomach and colon, weighed, and incubated in $1 \mathrm{ml}$ PBS and frozen. To determine the residual nitroxide concentration in the tissue, the frozen samples were thawed and volumes of $100 \mu$ l were drawn into Teflon capillary, placed in the electron paramagnetic resonance cavity, and the electron paramagnetic resonance spectrum of the TEMPOL was recorded. Using a control solution of TEMPOL of a known concentration, the residual nitroxide concentration in each tissue sample was calculated from the intensity of the electron paramagnetic resonance signal, knowing the weight of the tissue sample. Figure 2 shows the time dependence of the residual nitroxide in gastric and colonic mucosa. No nitroxide was detected in these tissues 24 hours after the administration of TEMPOL. The main route through which nitroxide stable radicals decay in tissue is by Such hydroxylamines are oxidisable to nitroxide upon re-oxygenation of the tissue. Although TEMPOL permeation into the colonic mucosal cells is instantaneous, several factors affect time dependence of the concentration of TEMPOL in the colonic mucosa: (a) mechanical clearance down the gastrointestinal tract; (b) intake from the stomach; (c) diffusion into the body across the colonic wall; (d) reduction to the respective hydroxylamine. Figure 2 shows that significant concentrations of TEMPOL are present in both gastric mucosa and colonic mucosa for quite a long period.

\section{TNB/ethanol induced colitis}

Intracolonic administration of TNB/ethanol resulted in extensive haemorrhagic and ulcerative damage to the distal colon, as previously reported. As seen in Figs 3-7, this damage was reflected by extensive colonic lesions, increase reduction to their respective hydroxylamines. 


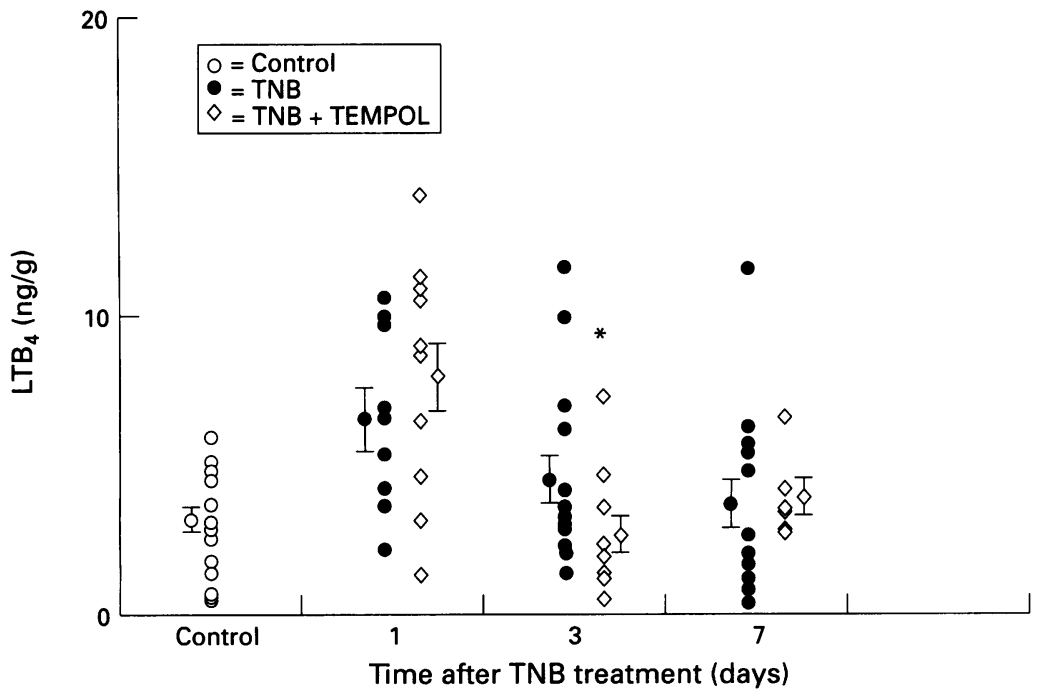

Figure 6: Effect of TEMPOL on colonic mucosal $L T B_{4}$ generation in TNB/ethanol treated rats. Experimental conditions as detailed in Fig 3. The colon was isolated, washed, the mucosa was scraped, extracted, and colonic mucosal $L T B_{4}$ generation was determined as described in Methods. Results are mean (SEM). * Significantly different from TNB treated rats only $(p<0.05)$.

in colon weight, increase of $\mathrm{LTB}_{4}$ generation and myeloperoxidase activity. TEMPOL, when given by itself, decreased $\mathrm{LTB}_{4}$ generation without affecting the other parameters. Intragastric administration of TEMPOL $(0.5 \mathrm{~g} / \mathrm{kg} / \mathrm{bw})$ in TNB treated rats did not affect $\mathrm{LTC}_{4}$ generation at all and reduced colonic weight, myeloperoxidase activity, and $\mathrm{LTB}_{4}$ only sporadically, but it significantly decreased mucosal lesion area after one, three, and seven days (Figs 3-7). Coadministration of TNB and TEMPOL intrarectally did not significantly affect the extent of damage induced after 24 hours by TNB: 503 (115) $\mathrm{mm}^{2}(\mathrm{n}=9)$.

In TEMPOL+TNB treated rats the effect of TEMPOL on the morphological appearance was less remarkable than its effect on the macroscopic appearance of the mucosa. One and three days after TNB administration in all rats, section through the colonic wall showed widespread mucosal ulcerations with oedema and an acute inflammatory cell exhudate in the

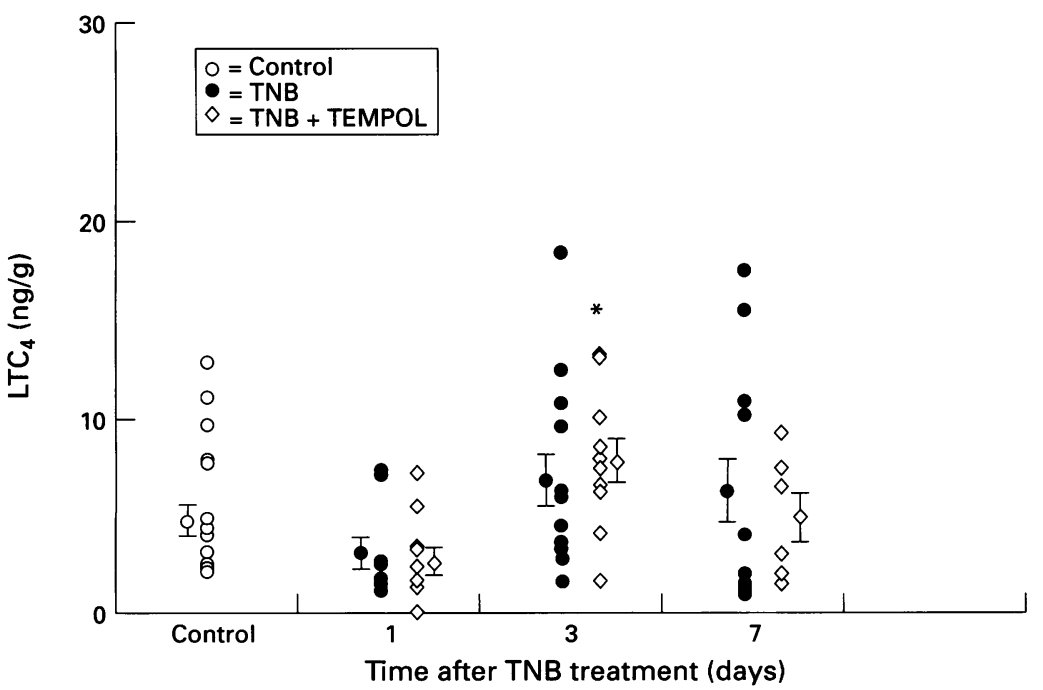

Figure 7: Effect of TEMPOL on colonic mucosal $L_{T} C_{4}$ generation in TNB/ethanol treated rats. Experimental conditions as detailed in Fig 3. The colon was isolated, washed, the mucosa was scraped, extracted, and colonic mucosal LTC $C_{4}$ generation was determined as described in Methods. Results are mean (SEM). ^Significantly different from control $(p<0 \cdot 05)$. lamina propria, extending also into the muscularis propria. Cross sections through the intestinal wall of rats treated with TNB and TEMPOL showed similar findings, albeit with slight decrease in the inflammatory infiltrate in the lamina propria and muscularis propria. Morphological examination of colonic sections obtained from TNB treated rats after one week of TEMPOL treatment showed, in $50 \%$ of them, relative protection of the mucosa. The necrosis was patchy affecting mainly the mucosa and submucosa. The mucosal ulcerations were superficial and less extensive than those seen in rats treated with TNB.

\section{Acetic acid induced colitis}

Acetic acid induced extensive colitis. Twenty four hours after its administration, the lesion area was 372 (48) $\mathrm{mm}^{2}$ (Fig 8). Myeloperoxidase activity increased from 1.5 $(0.5) \mathrm{U} / \mathrm{g}$ in saline treated rats to $3.5(0.7) \mathrm{U} / \mathrm{g}$ in acetic acid treated rats (Fig 9). Mucosal $\mathrm{LTB}_{4}$ and $\mathrm{LTC}_{4}$ generation was also significantly increased in acetic acid treated rats, compared with saline treated controls $(p<0.05)$ (Figs 10 and 11).

In rats treated with TEMPOL immediately after induction of damage with acetic acid, there was a significant reduction in the lesion area (Fig 8) but not in the wet weight (Fig 12). The reduction in lesion area started at a dose of $0.1 \mathrm{~g} / \mathrm{kg} / \mathrm{bw}$ and reached its maximal effect of $87 \%$ reduction at a dose of $0.5 \mathrm{~g} / \mathrm{kg} / \mathrm{bw}$ (Table). The protection provided by TEMPOL was accompanied by a two to threefold decrease in mucosal myeloperoxidase activity (Fig 9), $\mathrm{LTB}_{4}$ (Figure 10), and $\mathrm{LTC}_{4}$ generation (Fig 11). Administration of five doses of TEMPOL to acetic acid treated rats before and after damage induction did not provide further protection compared with that in rats treated with a single dose of TEMPOL. Superoxide dismutase administration, immediately after damage induction, had no protective effect on the colonic mucosa, lesion area being $310(80) \mathrm{mm}^{2}(\mathrm{n}=10)$ and segmental weight $1.27(0.12) \mathrm{g} / 10 \mathrm{~cm}(\mathrm{n}=10)$. Intragastric administration of bovine serum albumin also did not protect against acetic acid induced colonic damage (results not shown).

Histological sections of colonic segments obtained from 10 of 10 acetic acid treated rats showed widespread deep ulcerations with an extensive acute inflammatory cell exhudate. There was marked oedema with haemorrhages in the submucosa with an extension of the infiltrate into the muscularis propria (Fig 13). In contrast, the colonic wall of eight of nine rats treated with TEMPOL $(0.5 \mathrm{~g} / \mathrm{kg} / \mathrm{bw})$ showed an intact mucosa, with only a mild inflammatory infiltrate confined to the mucosa (Fig 14). In one rat the protection provided by TEMPOL was less effective and mild mucosal ulceration was present.

\section{Discussion}

Reactive oxygen metabolites mediate cell injury. Oxygen derived free radicals are generated by 
Figure 8: Effect of TEMPOL on lesion area in acetic acid treated rats. Colitis was induced in rats by intracaecal

administration of $2 \mathrm{ml} \mathrm{5 \%}$ acetic acid as described in Methods with or without coadministration of TEMPOL $0.5 \mathrm{~g} / \mathrm{kg} / \mathrm{bw}$, intragastrically. Rats were killed 24 hours after damage induction, the colon was isolated, and lesion area measured. Results are mean (SEM). * Significantly different from control $(p<0.05)$

†Significantly different from acetic acid $(p<0 \cdot 05)$.

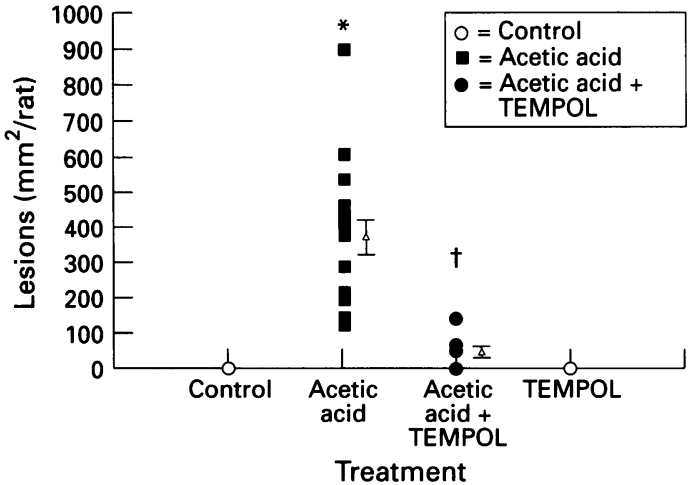

several sources, including stimulated polymorphonuclear cells, eosinophils, xanthine oxidase, colonic bacteria, and epithelial lipooxygenase, all of which are present in the inflamed bowel of inflammatory bowel disease patients. Several strategies for drug intervention specifically directed at the attenuation of oxidative stress have been considered. These include blocking of $\mathrm{O}_{2}{ }^{--}$formation by phagocytes, scavenging of $\mathrm{O}_{2} \cdot-$ before it can react with iron, binding iron so that it does not start the oxidation-reduction cycle, and scavenging $\mathrm{OH}$ or $\mathrm{HOCl}$. The primary defence against oxidative insult to tissue includes superoxide dismutase, catalase, and glutathione peroxidase. ${ }^{5}$ Superoxide dismutase and catalase were shown, in rats, to reduce intestinal damage induced by ischaemia reperfusion ${ }^{22}$ and also experimental colitis. ${ }^{52-25}$ They were also shown to be effective in uncontrolled clinical trials in human inflammatory bowel disease. ${ }^{26} 27$ The short half life of exogenously given superoxide dismutase, however, and its inability to penetrate into cells where superoxide is formed, limited the potential of this treatment and led to a search for cell permeable compounds possessing superoxide dismutase mimic activity. ${ }^{28} 29$

The results presented in Fig 1 clearly show that TEMPOL immediately partitions into mucosal cells. After its intragastrically administration, TEMPOL partitions into both gastric and colonic mucosa and persists there for several hours (Fig 2). TEMPOL is a nontoxic, cyclic nitroxide stable radical, which

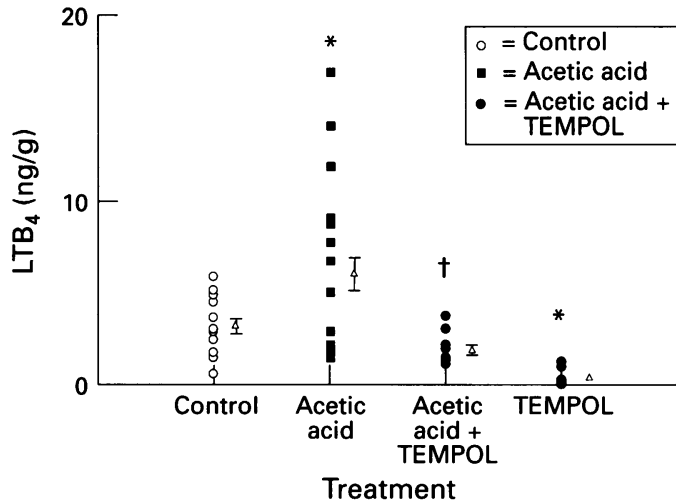

Figure 10: Effect of TEMPOL on colonic mucosal $\mathrm{LTB}_{4}$ generation in acetic acid treated rats. Experimental conditions as detailed in Fig 8. The colon was isolated, washed, the mucosa was scraped, extracted, and colonic mucosal $\mathrm{LTB}_{4}$ generation was determined as described in Methods. Results are mean (SEM). * Significantly different from control $(p<0.05)$. † Significantly different from acetic acid $(p<0 \cdot 05)$.

blocks biological damage by breaking chain reactions through selective termination reactions with deleterious free radicals. ${ }^{13}$ In this study, intragastrically administration of TEMPOL immediately after the induction of colitis, by acetic acid provided significant and impressive protection. The protective effect of TEMPOL was reflected by a dose dependent decrease in the lesion area and was accompanied by a significant decrease in the level of the inflammatory mediators. TEMPOL provides less remarkable protection against injury induced by $\mathrm{TNB} /$ ethanol. In this model of experimental colitis the protection reflected by a decrease in the lesion area was not correlated with histological appearance or with significant decrease in the generation of the inflammatory mediators. The different type of insult in the two models might be responsible for the different protective effect of TEMPOL. The injury induced by acetic acid is superficial affecting the mucosa, whereas in the TNB model the damage is more extensive and extends also to the muscularis propria. Intrarectal administration of TEMPOL did not provide protection from TNB induced damage. Different modes of TEMPOL administration may have different efficacy.

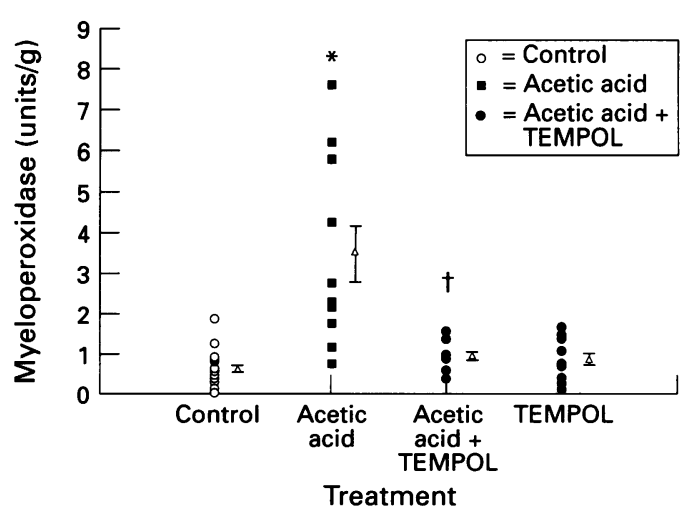

Figure 9: Effect of TEMPOL on colonic myeloperoxidase activity in acetic acid treated rats. Experimental conditions as detailed in Fig 8. The colon was isolated, the mucosa was scraped, and myeloperoxidase activity determined as described in Methods. Results are mean (SEM).

$\star$ Significantly different from control $(p<0.05)$.

+ Significantly different from acetic acid $(p<0.05)$.

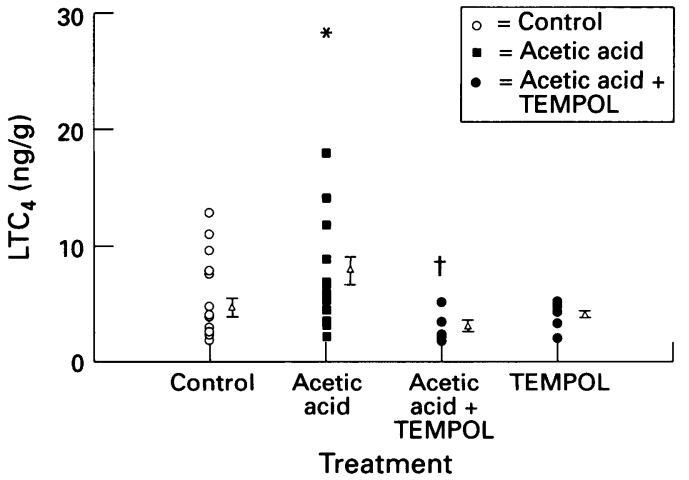

Figure 11: Effect of TEMPOL on colonic mucosal LTC generation in acetic acid treated rats. Experimental conditions as detailed in Fig 8. The colon was isolated, washed, the mucosa was scraped, extracted, and colonic mucosal LTC $\mathrm{C}_{4}$ generation was determined as described in Methods. Results are mean (SEM). ^Significantly different from control $(p<0 \cdot 05)$. + Significantly different from acetic acid $(p<0.05)$. 
Figure 12: Effect of TEMPOL on colonic weight in acetic acid treated rats. Experimental conditions as detailed in Fig 8. The colon was isolated and its $10 \mathrm{~cm}$ distal segment weighed. Results are mean (SEM). $\star$ Significantly different from control $(p<0.05)$.

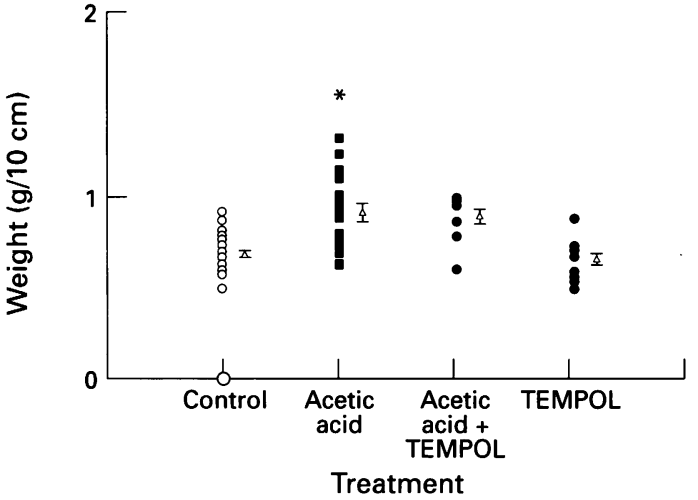

The optimal schedule and mode of administration necessary to obtain maximal protection deserve further clarification.

Several mechanisms, all of which entail an interception of paramagnetic species, underlie the protection provided by nitroxides: both the nitroxide and its respective hydroxylamine can react with $\mathrm{O}_{2}^{--}$yielding $\mathrm{O}_{2}$ and $\mathrm{H}_{2} \mathrm{O}_{2}$, whereas the concentration ratio of the oxidation-reduction couple remains time invariant and independent of $\mathrm{O}_{2}^{-}$flux. ${ }^{30}$ Recently, the nitroxide and its respective oxoammonium cation were shown to also act as a superoxide dismutase mimic rapidly reacting with $\mathrm{O}_{2}^{-}$ yielding oxygen and $\mathrm{H}_{2} \mathrm{O}_{2} \cdot{ }^{31}$ Unlike superoxide dismutase, which does not enter into cells, and is not anticipated to protect from the deleterious action of intracellular $\mathrm{O}_{2}^{-}$, nitroxides can remove both intra and extracellular radicals. The physiological function of superoxide dismutase, which is present in cells of all aerobes, is to dismutate $\mathrm{O}_{2}^{-}$converting it to $\mathrm{O}_{2}$ and $\mathrm{H}_{2} \mathrm{O}_{2}$. Yet, superoxide dismutase cannot protect from $\mathrm{H}_{2} \mathrm{O}_{2}$ induced damage. Conversely, nitroxides can compete with $\mathrm{H}_{2} \mathrm{O}_{2}$ for the oxidation-reduction active transition metal ions, maintain iron and copper as $\mathrm{Fe}(\mathrm{III})$, and $\mathrm{Cu}(\mathrm{II})$, and pre-empt the injurious Fenton reaction. In addition, nitroxides were found to protect hypoxic cells where reactive oxygen species are practically absent. Nitroxides protect hypoxic Chinese hamster cells against t-BuOOH induced toxicity, which is catalysed by transition metals ${ }^{13}$ and also against cytotoxic drugs through reaction with and thus removal of the deleterious semiquinone radicals of mitomycin $\mathrm{c}^{32}$ and streptonigrin. ${ }^{33}$

In this study, in acetic acid induced colitis, superoxide dismutase was found to have no effect on the extent of the mucosal injury. The

Effect of various doses of TEMPOL on acetic acid induced colonic damage

\begin{tabular}{lcc}
\hline $\begin{array}{l}\text { TEMPOL dose } \\
(g / \mathrm{kg} / \mathrm{bw})\end{array}$ & $\begin{array}{l}\text { Rats } \\
(\mathrm{n})\end{array}$ & $\begin{array}{l}\text { Lesion area } \\
\left(\mathrm{mm}^{2}\right)\end{array}$ \\
\hline None & 18 & $372(48)$ \\
$0 \cdot 1$ & 8 & $145(36)^{\star}$ \\
$0 \cdot 3$ & 10 & $113(20)^{\star}$ \\
$0 \cdot 5$ & 8 & $47(17)^{\star}$ \\
$0 \cdot 75$ & 7 & $47(20)^{\star}$
\end{tabular}

Colitis was induced by intracaecal injection of $2 \mathrm{ml} \mathrm{5 \%}$ acetic acid, as described in Methods. Treated rats received

intragastrically various doses of TEMPOL. Rats were killed 24 hours after damage induction and damage was assessed. $\star$ Significantly different from acetic acid treated rats,

Mann-Whitney and Student $t$ test. $n=N u m b e r$ of experiments.

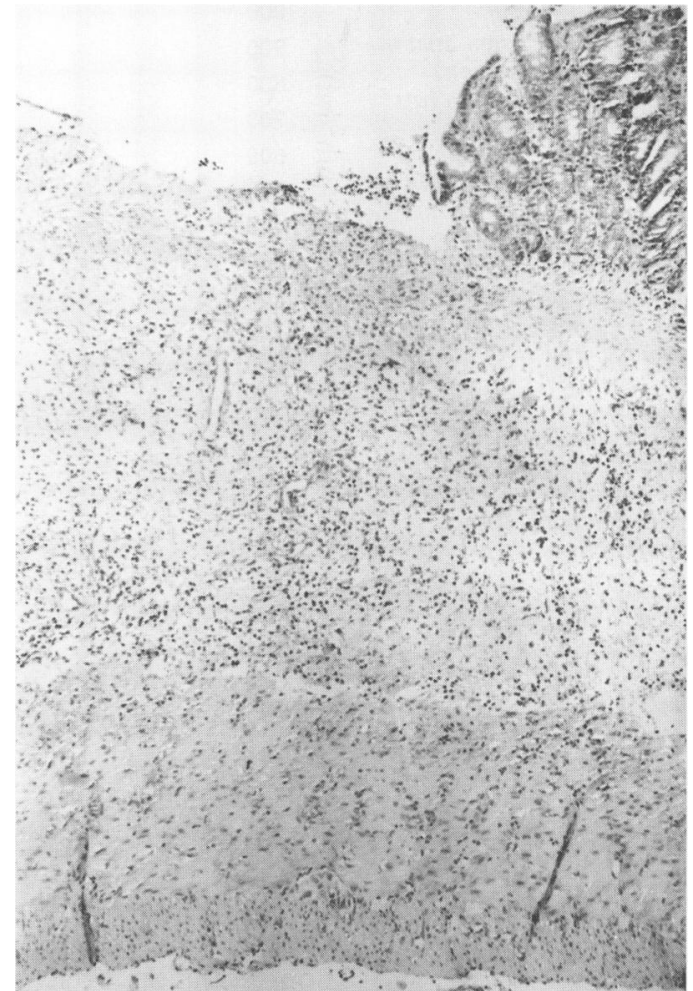

Figure 13: Histological section from the colon of a rat with acetic acid induced colitis. Note the deep ulcer and the extensive inflammatory infiltrate in the submucosa extending into the muscularis propria (haematoxylin and eosin, original magnification $\times 10)$.

protection afforded by nitroxides, as presented here, was greater than that reported to be afforded by superoxide dismutase in mice and guinea pigs against acetic acid induced colitis and that provided by catalase against acetic acid induced colitis in rats. ${ }^{23}$ However, superoxide dismutase was reported to almost completely protect isolated rabbit colonic loops exposed to TNB/ethanol. ${ }^{24}$ The different species and experimental designs are probably responsible for the different results. The greater efficacy of nitroxides in amelioration of experimental colitis is probably due to their penetration of cell membranes and, thus, their capability to neutralise intracellular free radicals and oxidation-reduction active labile transition metal ions.

In the acetic acid model and seven days after damage induction with TNB/ethanol, the protective effect of TEMPOL was accompanied by a significant decrease in myeloperoxidase activity. The mucosal value of myeloperoxidase activity was shown to correlate with the severity of the inflammatory response in experimental colitis ${ }^{34}$ and its reduced activity herewith seen, further confirms the protective effects of TEMPOL. For acetic acid treated rats the protective effect of TEMPOL was accompanied by significant decrease in mucosal $\mathrm{LTB}_{4}$ and $\mathrm{LTC}_{4}$ generation. In TEMPOL treated rats only 72 hours after damage induction with $\mathrm{TNB} / \mathrm{ethanol}$, the generation of $\mathrm{LTB}_{4}$ was significantly decreased whereas $\mathrm{LTC}_{4}$ generation was not reduced. Decreased generation of mucosal leukotrienes may contribute to amelioration of tissue injury as $\mathrm{LTB}_{4}$ has an important role in leucocyte chemotaxis and activation and $\mathrm{LTC}_{4}$ in 
Figure 14: Cross section of the colonic wall in a rat treated with acetic acid and TEMPOL. Note that the mucosa is intact and shows only a mild inflammatory infiltrate (haematoxylin and eosin, original magnification $\times 10$ ).

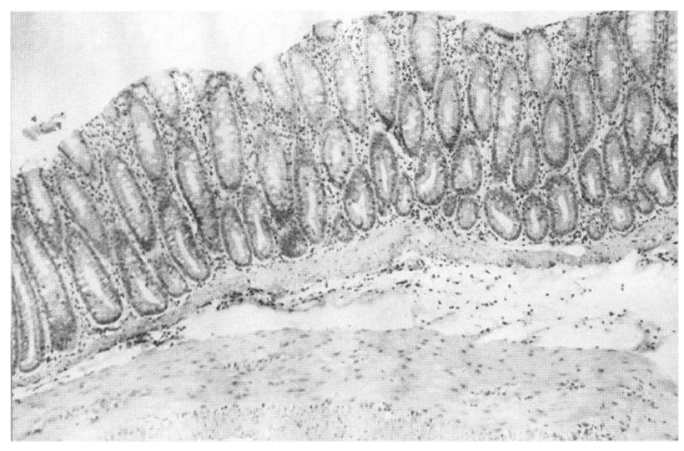

vascular vasoconstriction, ${ }^{23}$ which may accelerate mucosal injury and generation of more oxygen free radicals. Moreover, as oxygen free radicals are also generated by prostaglandin synthetase and lipooxygenase, ${ }^{35}$ their decreased activity may result in decreased generation of these radicals, further contributing to mucosal protection.

In the acetic acid model, with or without TEMPOL there were no significant intragroup correlations between lesion area, colonic weight, and the various biochemical parameters measured. In the TNB model without TEMPOL there were a significant correlation, at 24 hours, between myeloperoxidase activity and lesion area $(r=0 \cdot 5)$ and weight $(r=0 \cdot 6)$. At one week in TEMPOL+TNB treated rats there was a significant correlation between lesion area and $\mathrm{LTB}_{4}$ generation $(r=0 \cdot 6)$. The lack of significant intragroup correlations among the various variables within each group probably results from different biological behaviour of individual animals within the group.

In summary, this study shows that both the acetic acid and TNB/ethanol models of colitis can be manipulated by TEMPOL, a non-toxic, cell permeable, cyclic nitroxide. The protection afforded by TEMPOL further implicates oxygen derived free radicals in the pathogenesis of experimental colitis and provides a novel approach towards the possible treatment or prevention of inflammatory bowel disease, or both.

This research was partly supported by grant no 309/931 from the Israel Science Foundation of the Israel Academy of Science, and a grant from the Ministry of Health, Jerusalem, Israel.

1 Kirsner JD, Shorter RG. Recent developments in nonspecific inflammatory bowel disease. $N$ Engl F Med 1982; 306: 775-85, 837-48.

2 Schreiber S, Raedler A, Stenson WF, MacDermott RP. The role of the mucosal immune system in inflammatory bowel dis

3 MacDermott RP, Stenson WF. Alterations of the immune system in ulcerative colitis and Crohn's disease. Adv Immunol 1988; 42: 285-328.

4 Grisham MB, Granger DN. Neutrophil mediated mucosal injury. Role of reactive oxygen metabolites. Dig Dis $\mathrm{Sci}$ 1988; 33: 6-15S.

5 Babbs CF. Oxygen radicals in ulcerative colitis. Free Radical Biol Med 1992; 13: 169-81.

6 Babbs CF. Hypothesis paper: Free radicals and the etiology of colon cancer. Free Radical Biol Med 1990; 8: 191-200.

7 Marklund S. Distribution of CuZn superoxide dismutase and $M n$ superoxide dismutase in human tissues and extracellular fluids. Acta Physiol Scand 1980; III: 9-23.

8 Marklund SL. Extracellular superoxide dismutase and other superoxide dismutase isoenzymes in tissues from nine superoxide dismutase isoenzymes in tissues from
mammalian species. Biochem $\mathcal{f} 1984 ; 222: 649-55$.
9 Dallegri F, Ottonello L, Ballestrero A, Bogliolo F, Ferrandeo F, Patrone F. Cytoprotection against neutrophil derived hypochlorous acid: a potential mechanism for the therapeutic action of 5-aminosalicylic acid in ulcerative colitis. Gut 1990; 31: 184-6.

10 Allgayer H, Rang S, Hofer P, Kruls W, Retey J, Gugler R. Superoxide radical inhibition by sulfasalazine (SAZ) and Superoxide radical inhibition by sulfasalazine (SAZ) and aminosalicylates: extra vs

11 Ahnfelt-Ronne I, Nielsen OH, Christensen A, Langholz E, Binder V, Riis P. Clinical evidence supporting the radical scavenger mechanism of 5-aminosalicylic acid. Gastroenterology 1990: 98: 1162-9.

12 Allgayer $\mathrm{H}$. Clinical relevance of oxygen radicals in inflammatory bowel disease - facts and fashion. Klin Wochenschr 1991; 69: 1001-3.

13 Mitchell JB, Samuni A, Krishna MC, de Graff WG, Ahn MS, Samuni U, et al. Biologically active metal-independent superoxide dismutase mimics. Biochem 1990; 29: pendent $2802-7$.

14 Gelvan D, Saltman P, Powell SR. Cardiac reperfusion damage prevented by a nitroxide free radical. Proc Natl Acad Sci USA 1991; 88: 4680-4.

15 Hahn SM, Tochner Z, Krishna MC, Glass J, Wilson L, Samuni A, et al. TEMPOL, a stable free radical is a novel murine radiation protector. Cancer Res 1992; 52: 1750-3.

16 Rachmilewitz D, Karmeli F, Okon E, Samuni A. A novel antiulcergenic stable radical prevent gastric mucosal lesions in rats. Gut 1994; 35: 1181-8.

17 Eliakim R, Karmeli F, Okon E, Rachmilewitz D. Ketotifen effectively prevents mucosal damage in experimental colitis. Gut 1992; 33: 1498-503.

18 Bradley PP, Pirebat DA, Christensen RD, Rothstein G. Measurement of cutaneous inflammation: estimation of neutrophil content with an enzyme marker. $\mathcal{f}$ Invest Dermatol 1982; 78: 206-9.

19 Bailar JC, Young EM. Troxalato salts. Inorg Synth 1939; 1: 35-8.

20 Lai CS, Froncise W, Hopewood LE. An evaluation of paramagnetic broadening agents for spin probe studies of intact mammalian cells. Biophys $\mathcal{F} 1987 ; 52: 625-8$.

21 Samuni A, Carmichael AJ, Russo A, Mitchell JB, Riesz P. On the spin trapping and ESR detection of oxygenderived radicals generated inside cells. Proc Natl Acad Sci USA 1986; 83: 7593-7.

22 Droy-Lefaix MT, Drovet Y, Gerand G, Hosford D, Braquet P. Superoxide dismutase (SOD) and the PAF antagonist (BNS221) reduce small intestinal damage induced by ischemia-reperfusion. Free Radic Res Commun induced by ischemia-r.

23 Fretland DJ, Widomski DL, Anglin CP, Walsh RE, Levin S, Riley D, et al. Superoxide dismutase (SOD) modulates acetic acid-induced colitis in rodents. Gastroenterology 1991; 100: A581.

24 Burakoff R, Zhao L, Joseph I, Kor H, Rosenfeld W. SOD prevents colitis and attenuates eicosanoid release and motility changes in trinitrobenzene sulfonic acid rabbit colitis. Gastroenterology 1991; 100: A565.

25 Keshavarzian A, Haydeck J, Zabihi R, Doria M, D'Astice $M$, Sorenson JRJ. Agents capable of eliminating reactive oxygen species, catalase, WR-2721, or Cu(II) $(3,5$ DIPS decrease experimental colitis. Dig Dis Sci 1992; 37: 1866-73.

26 Emerit J, Pelletier S, Tosoni-Verlignue D, Mollet M. Phase II trial of copper zinc superoxide dismutase (CuZnSOD) in the of copper zinc superoxide dismutase (CuZnSOD) in the treatment

27 Emerit J, Pelletier S, Likforman J, Pasquier C, Thuillier A. Phase II trial of copper zinc superoxide dismutase (CuZnSOD) in the treatment of Crohn's disease. Free Radic Res Commun 1991; 12-13: 563-9.

28 Brigelius R, Spottl R, Bors W, Lengfeider E, Saran M, Weser U. Superoxide dismutase activity of low molecular weight $\mathrm{Cu}^{2+}$ chelates studied by pulse radiolysis. FEBS Lett 1974; 47: 72-5.

29 Koppenol WH, Levine F, Hatmaker TL, Epp J, Rush JD. Catalysis of superoxide dismutation by manganese aminopolycarboxylate complexes. Arch Biochem Biophys 1986; 251: 594-9.

30 Samuni A, Krishna CM, Riiesz P, Finkelstein E, Russo A. A novel metal free low molecular weight superoxide dismutase mimic. $\mathcal{F}$ Biol Chem 1988; 263: 17921-4.

31 Krishna MC, Graham DA, Samuni A, Mitchell JB, Russo A. Oxoammonium cation intermediate in the nitroxide catalyzed dismutation of superoxide. Proc Natl Acad Sci USA 1992; 89: 5537-41.

32 Krishna MC, DeGraff W, Tamura S, Gonzalez FJ, Samuni A, Russo A, et al. Mechanisms of hypoxic and aerobic cytotoxicity of mitomycin c in Chinese hamster V-79 cells. Cancer Res 1991; 51: 6622-8.

33 Krishna CM, Halevy FR, Zhang R, Gutierrez PL, Samuni A. Modulation of streptonigrin cytotoxicity by nitroxide SOD mimics. Free Radic Biol 1994; 17: 379-8.

34 Rachmilewitz D, Simon PL, Schwartz LW, Griswold DE, Fondacaro JD, Wasserman MA. Inflammatory mediators

35 Craven PA, Pfanstiel J, De Rubertis FR. Role of reactive oxygen in bile salt stimulation of colonic epithelial prooxygen in bile salt stimulation of colonic
liferations. $₹$ Clin Invest 1986; 177: 850-9. 